\title{
Guest Comment: Early Years Are Important in the STEM Pipeline
}

\author{
Robert D. Koob \\ Department of Chemistry \\ University of Northern lowa \\ Cedar Falls, lowa 50614 USA
}

\begin{abstract}
While we have known for nearly three decades that America was not graduating enough of its citizens in the areas of Science, Technology, Engineering and Mathematics (STEM), a steady influx of international students ameliorated the impact until recently. Heightened security concerns coupled with the rapid growth of higher education opportunities in developing countries, particularly India and China, have reawakened interest in our own "pipeline" issues.
\end{abstract}

Predictably, attention is already being focused on teaching STEM courses in high school and college. That seems to be where we generally believe teaching of science begins. While such attention is important and appropriate, it is insufficient to our needs. We've lost a good share of our potential students in their early years.

In a very real sense, science teaching in America is a victim of its own success. Attention to content and rigor, encouraging only the most able to move forward in STEM disciplines, has created the worlds leading economy and number one technological innovator. It is hard to argue with such success, but clearly we have not created a sustainable system if our STEM pipeline is inadequate to our needs.

We seem, in our eagerness to teach the discoveries of past scientists, to have overlooked teaching the joy of discovery to potential future scientists. The content of science appears to have pushed out the process of science in our curricula. The creative process, indeed, can be messy and slow and difficult to integrate into a crowded lesson plan or school day. Few teachers have been provided with the insight on how to do this well in their own science education. There are a few examples, however, that show us it is entirely possible for students of diverse backgrounds and interests to exercise their creative abilities and learn to test and adopt or discard hypotheses readily.

Ask any parent what their child did with that large box that their washer or dryer came in and how this is possible becomes immediately apparent. Imagine all that energy and creativity under the guidance of a patient and understanding teacher that can present new challenges regularly.

Educational theorists will detect beneath my words a lament that the behaviorism has gained prominence over constructivism in today's classroom environment. I have neither the space nor the capability of pursuing that argument. What I am suggesting is that to create a sustainable pipeline in the STEM disciplines we would do well to find room for both as we teach teachers, and as teachers approach science in their lower grade classrooms. If we do not, many of those students that would take joy in high school and college science will never make it there.

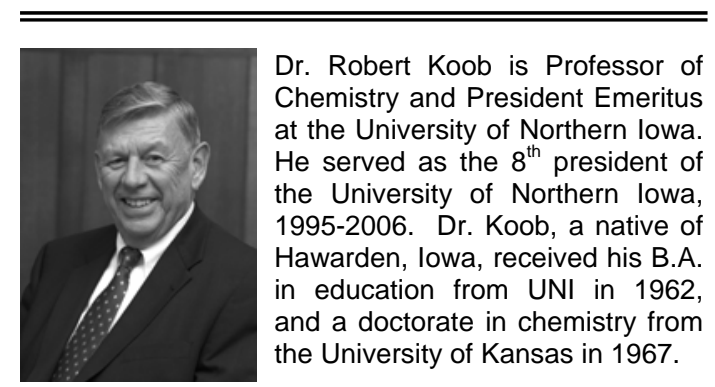

